Original article

\title{
The interregional disparity in the choice of health care utilization among elderly in India
}

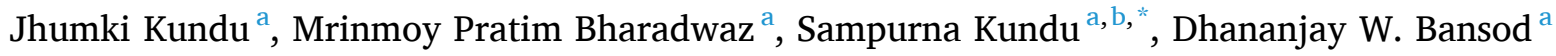 \\ ${ }^{a}$ International Institute for Population Sciences, Deonar, Mumbai, 400088, India \\ ${ }^{\mathrm{b}}$ Centre of Social Medicine and Community Health, Jawaharlal Nehru University, Delhi, 110067, India
}

\section{A R T I C L E I N F O}

\section{Keywords:}

Disparity

Elderly

Health care utilization

Inpatient

Private

Public

Andersen model

India

\begin{abstract}
A B S T R A C T
Background: The elderly population in India is expanding fast, which indicates a growing share of people with more specialized needs for health and support. One of the prominent issues is the choice of health care services among the elderly, leading to its impact on health expenditure. Under Andersen's Health Behavioral Model, this study attempts to examine the nature of interregional disparity in the choice of health care services, along with investigating the choice-making in hospitalization services between private and public sources among the elderly. Besides, this study also comprises the regional dynamics of geriatric health care utilization.

Methods: The current study uses data from the NSS, 75th round. The difference between choice in healthcare utilization and inpatient out-of-pocket (OOP) expenditure showed using the $t$-test and Z-test. The study also uses binary logistic regression analysis to explore the association of predisposing, enabling, and need factors with health services utilization.

Results: The results suggest that the utilization of public facilities for inpatient services was very low, except in eastern and north-eastern states. Caste, education, monthly per capita expenditure (MPCE), and need for surgery were the main factors explaining the choice of either public or private facilities.

Conclusion: The findings of the study stresses the need to provide suitable health facilities for India's senior population in the hospital, which may help policymakers better understand their health care needs.
\end{abstract}

\section{Introduction}

Population aging is one of the most concerning issues of this century. Almost all the world countries are experiencing rapid population aging, which has significant consequences on their socio-economic development. The aging population brings disability, frailty, co-morbidity, and poor health, leading to higher health care utilization and concomitant high out-of-pocket expenditure. The utilization of health services is a complex behavioural phenomenon corresponding to the availability, quality, cost, comprehensiveness of services, and the users' sociocultural structure, health beliefs, and personal characteristics. ${ }^{1}$ It is the choice of health care services that decides the magnitude of out-of-pocket health spending. The utilization of private or public health services largely depends on the socioeconomic and demographic characteristics of the elderly population.

In India, private healthcare providers dominate the healthcare facilities. ${ }^{2}$ In the early 1950s, the share of the private sector was merely
$8 \%$ of the total healthcare market, ${ }^{3}$ which has now risen to $70 \%$ of all the hospitals and $40 \%$ of total hospital beds. ${ }^{4}$ According to the National Sample Survey ${ }^{5}$ estimates, the private sector caters to $75 \%$ of the outpatients and $62 \%$ of the inpatients that turn up for medical care. NSS survey results showed that 12 out of 20 states in rural areas and 17 out of 21 states in urban areas registered a decline in government services utilization for inpatient hospitalization. ${ }^{6}$ Furthermore, another study, employing data from the NSS over the last two decades, showed a decline in the share of utilization from public hospitals. ${ }^{7}$ A government-sponsored health insurance scheme's utilization data indicate that $70 \%$ of India's hospitalization takes place in the private sector. ${ }^{8}$

According to WHO In India, private expenditures constitute up to $70 \%$ of total health expenditures and more than $40 \%$ in Russia and China. ${ }^{9}$ As the health sector grew, it became less reliant on out-of-pocket spending. Total out-of-pocket expenditures more than doubled in low and middle-income countries from 2000 to 2017 and increased by $46 \%$ in high-income countries. However, it grew slower than public spending

\footnotetext{
* Corresponding author. Centre of Social Medicine and Community Health, Jawaharlal Nehru University, Delhi, 110067, India.

E-mail addresses: jhumkikundu16@gmail.com (J. Kundu), mpb06197@hotmail.com (M.P. Bharadwaz), sampurna34@gmail.com (S. Kundu), dhananjay@iips.net (D.W. Bansod).
} 
in all income groups. ${ }^{10}$ In India, private health care services are almost four times costlier than public ones. ${ }^{11}$ Still, more than $61 \%$ of the elderly seek health services from private hospitals. For the oldest-old group ( 80 years and above), private hospitalization is close to two-thirds of the total. ${ }^{12} \mathrm{~A}$ cross-country study reveals that the private inpatient health care utilization among the older Indians is the highest among countries like China, Ghana, Russia, and South Africa. ${ }^{13}$ There is, however, contrary to evidence that with increasing age, people are likely to avail themselves of public health services. ${ }^{14}$ In this context, it is pertinent to investigate further the choice of inpatient health care services (public vs. private) for the elderly in India and the factors determining the same.

In India, the monthly per capita health spending of households having at least one elder member is 3.8 times higher than those with nonelderly households. ${ }^{15}$ Recently, a study found that almost $30 \%$ of the households in India with at least one elderly, and 38\% of the households with two or more elderly experience catastrophic expenditure on health than only $20 \%$ of households with no elderly members. ${ }^{16}$ In health systems where out-of-pocket money is the predominant source for meeting medical cost, the opportunity of reaching out and obtaining appropriate health care services are constrained by the ability to pay. The same is India's case, where private health expenditure accounts for $82 \%$ of total health care spending ${ }^{17}$ which has grown exponentially in recent years, from 195 to 1283 billion Indian Rupees (INR) between 1994 and $2003 .^{18}$ More than $40 \%$ of hospitalized patients have to borrow money or sell household assets to meet health expenses, and an average of $24 \%$ are impoverished in the process. ${ }^{19}$ In low-income countries, direct out-of-pocket (OOP) payments are the principal means of health system financing. India is no exception, where OOP payments account for over $70 \%$ of the total health care financing. ${ }^{20}$ Such a predominant share of OOP payments is indicative of a highly regressive health care system: one that also intensifies poverty and ill fare. ${ }^{21}$

Apart from individual-level socio-economic issues that adversely affect affordability, several systemic factors underpin people's reduced ability, particularly the elderly, to pay for their healthcare. Despite the availability of several healthcare payment options in India, $83 \%$ of healthcare expenses are private and out-of-pocket (OOP). ${ }^{22}$ India's relatively unaccountable and inefficient public healthcare system has led to the evolution of a highly varied, unregulated, and most expensive private sector providing most of the healthcare, increasing vulnerability to catastrophic healthcare expenditure and poverty. ${ }^{23}$ It is also noteworthy that India's health delivery system varies according to region. The distribution of private sector facilities between states and territories is even more unequal than those in the public sector. These issues reflect the tendency to concentrate on better-off states and regions within them. ${ }^{24,25}$ Given variations in utilization, the healthcare facility's choices and factors influencing the decision are essential investigation areas. Earlier, a few studies examined the role of socioeconomic status and accessibility on the choice of public and private health facilities for reproductive and maternal and child health services. However, to our knowledge, no studies have been undertaken to understand the utilization of inpatient or outpatient care and factors determining the choice of usage specifically, at the provincial level.

\section{Theoretical framework}

In the past, researchers have developed several theoretical models to examine the factors determining health care utilization. Suchman's stages of illness and medical care (1965), Rosenstock's health belief model (1994), and Young's choice-making model (1981) are worth mentioning in this context. ${ }^{26-28}$ However, the most widely used model of health care utilization is Andersen's Health Behavioural Model (HBM) ${ }^{29}$ The HBM assumes that the choice of health care utilization is a type of individual behaviour. In effect, several socioeconomic, demographic, and health-related factors influence the individuals in question. The model categorizes them under three broad heads: predisposing factors, enabling factors, and need factors (Fig. 1).

Predisposing Factors: Some individuals tend to use services more than other individuals, where a tendency toward use can be predicted by individual characteristics that exist before the onset of specific episodes of illness. People with certain features are more likely to use health services even though those features are not directly responsible for health service use. Characteristics such as demographic, social structural, and attitudinal-belief variables are not directly responsible for health service use. Age and sex, for example, among the demographic variables, are intimately related to health and illness. However, they are still considered predisposing conditions as age is not considered a reason for seeking health care. Instead, people in different age groups have different types and amounts of illness and, consequently, different medical care patterns. Evidence suggests that people who have experienced health problems in the past are those most likely to make demands on the medical care system in the future. The social structure variables comprise occupation, education, social network, culture, family size, religion and residential mobility, and health beliefs such as attitude, knowledge, and values about health and health care services.

Enabling Factors: Even though individuals may be predisposed to use health services, some means must be available for them to avail those services. A condition that permits a family to act on a value or satisfy a need regarding health service use is enabling. Enabling conditions make health service resources available to the individual. It generally includes family resources such as income, level of health insurance coverage, community health facility, price of health care services, region, and place of stay (rural-urban).

Need Factors: Need for care is the most immediate cause of health service use, encompassing functional and health problems that generate the need for healthcare services. ${ }^{30}$ This definition takes into account specific disabilities or diseases that cause a person to seek medical health. It is considered an essential component in Health Behavioural Model (HBM) and is the primary determinant for healthcare utilization, including perceived need and evaluated need. ${ }^{29}$

\section{Methods}

\subsection{Sources of data and study design}

The 75th round of the National Sample Survey (NSS) survey adopted a stratified multistage sampling procedure to collect data. The survey interviewed a random sample of 113823 households spread over every

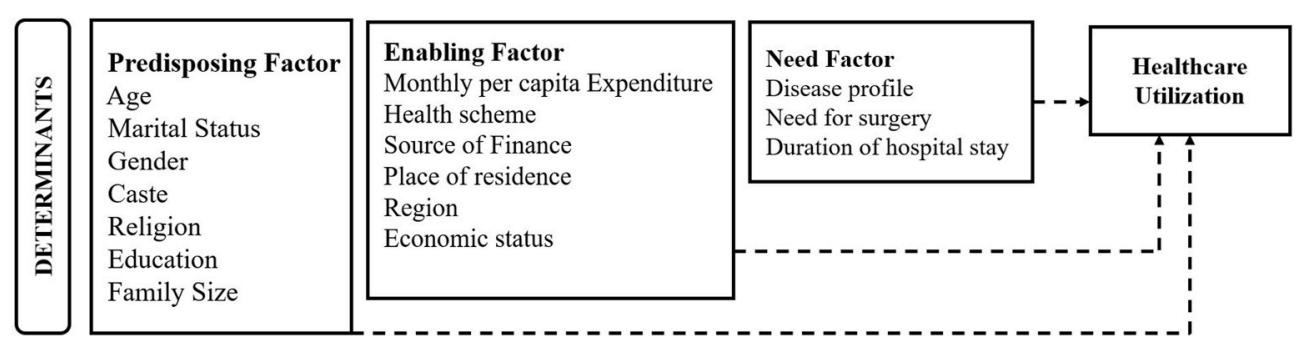

Fig. 1. Conceptual framework based on Health Behavioural Model. 
district's rural and urban areas across the country. In total, 44333 elderly population were surveyed. For the present study, we considered 12642 samples who had reported the utilization of inpatient health care services in the last 365 days preceding the survey. The study comprises of 7029 males and 5612 females.

Here, the elderly are those who fall under the age group of 60 years and above. The study's outcome variable is the choices of the hospital for which two types of health care services are taken into consideration: private and public/government inpatient health care. All the explanatory variables for the choice regarding health care utilization were chosen based on Andersen's Behavioural framework. The model considers all individual-level variables.

t-test and Z-test show the significant difference between the choice of health care utilization and inpatient OOP expenditure. Simultaneously, the binary logistic regression analysis is used to assess the association of predisposing age, gender, caste, religion, education, and household size. Thereby enabling MPCE, health scheme, place of residence, source of finance, economic dependence, region, and need factors such as ailment, need for surgery, and hospitalization duration with the utilization of health services (public and private). The results of logistic regression are presented by the odds ratio, with a $95 \%$ confidence interval (CI).

The equation of the logistic regression was the following,

$\operatorname{Logit}(Y)=\ln \left(\frac{p}{1-p}\right)=\mathrm{a}+\beta_{1} \mathrm{X}_{1}+\ldots+\beta_{\mathrm{i}} \mathrm{X}_{\mathrm{i}}+\epsilon$

Where $\mathrm{p}$ is the probability of the event, and $\mathrm{a}$ is the intercept, $B$ 's are regression coefficients, $x_{i}$ is a set of predictors, and $\varepsilon$ is an error term.

\section{Results and discussion}

\subsection{Characteristics of the sample individuals across regions}

Table 1 presents the socioeconomic and demographic characteristics of the population study across six different regions of the country. In our study majority of the elderly belong to the younger old group (56.5\%), and a very small proportion belonged to the "oldest old" category $(12.5 \%)$ which is similar to the finding of. ${ }^{31}$ The proportion of elderly male was higher than females in all six regions. The western region recorded the most top literate elderly(65.4\%), followed by the southern region (64.5) and the north-east region (59.6\%). The north-east region comprises more socially backward (SC/ST) elderly (37.1\%) compared to the other areas, while the southern region records the highest proportion of elderly of other backward classes (56.6\%). The sample of the study was predominantly rural $(61.3 \%)$. Nearly three-fourths of the sample respondents were economically dependent on others which is similar to the findings of. ${ }^{32}$ In all six regions, the predominant sources of health financing were household income and savings.

The majority of the elderly suffered from non-communicable diseases across all six regions (50.0\%). This is further supported by the researchers who state that three out of five elderly were suffering from at least one chronic NCD. ${ }^{33}$ This is also line with the study by ${ }^{34}$ who state that in India, the elderly persons are highly burdened with increasing prevalence of complicated non-communicable diseases.

The need for surgery of the elderly was more or less similar across all the regions. A considerable proportion of elderly (72.6\%) utilizing inpatient care was not covered under any health care schemes. The National Sample Survey (NSSO) data also revealed that in India, more than $82 \%$ of the elderly do not come under any health schemes. ${ }^{5}$

Table 1

Percent distribution of elderly by its Characteristics and regions.

\begin{tabular}{|c|c|c|c|c|c|c|c|c|}
\hline \multirow[t]{2}{*}{ Variable } & \multirow[t]{2}{*}{ Sub categories } & \multirow[b]{2}{*}{$\begin{array}{l}\text { Overall }(\mathrm{N}= \\
12641)\end{array}$} & \multicolumn{6}{|l|}{ Regions } \\
\hline & & & $\begin{array}{l}\text { Northern } \\
(2412)\end{array}$ & $\begin{array}{l}\text { Northeast } \\
(1084)\end{array}$ & $\begin{array}{l}\text { Central } \\
(1707)\end{array}$ & $\begin{array}{l}\text { Eastern } \\
(1958)\end{array}$ & $\begin{array}{l}\text { Western } \\
(1758)\end{array}$ & $\begin{array}{l}\text { Southern } \\
(3723)\end{array}$ \\
\hline \multirow[t]{3}{*}{ Age group } & $60-69(\%)$ & 56.54 & 54.74 & 63.95 & 55.36 & 54.49 & 59.44 & 57.13 \\
\hline & $70-79(\%)$ & 30.93 & 32.75 & 23.9 & 36.02 & 31.3 & 28.3 & 29.41 \\
\hline & 80 and above (\%) & 12.53 & 12.51 & 12.15 & 8.61 & 14.21 & 12.26 & 13.46 \\
\hline \multirow[t]{2}{*}{ Gender } & Male (\%) & 54.26 & 55.49 & 58.35 & 50.73 & 58.51 & 52.22 & 53.91 \\
\hline & Female (\%) & 45.74 & 44.51 & 41.65 & 49.27 & 41.49 & 47.78 & 46.09 \\
\hline \multirow[t]{2}{*}{ Education } & Illiterate & 42.68 & 50.28 & 40.36 & 59.29 & 45.03 & 34.56 & 35.49 \\
\hline & Literate & 57.32 & 49.72 & 59.64 & 40.71 & 54.97 & 65.44 & 64.51 \\
\hline \multirow[t]{3}{*}{ Caste } & SC/ST & 19.19 & 27.26 & 37.17 & 24.96 & 22.82 & 17.01 & 12.25 \\
\hline & OBC & 41.2 & 26.83 & 30.44 & 43.32 & 26.72 & 32.76 & 56.69 \\
\hline & Others & 39.61 & 45.91 & 32.39 & 31.72 & 50.46 & 50.23 & 31.06 \\
\hline \multirow[t]{3}{*}{ Religion } & Hindu & 77.16 & 72.22 & 55.9 & 85.35 & 88.15 & 82.76 & 74.38 \\
\hline & Muslims & 11.9 & 13.02 & 8.87 & 12.95 & 10.73 & 8.87 & 11.9 \\
\hline & Others* & 10.93 & 14.76 & 8.36 & 1.7 & 1.12 & 8.36 & 10.93 \\
\hline \multirow{2}{*}{$\begin{array}{l}\text { Place of } \\
\text { Residence }\end{array}$} & Rural & 61.35 & 62.45 & 70.81 & 67.88 & 66.2 & 52.5 & 59.29 \\
\hline & Urban & 38.65 & 37.55 & 29.19 & 32.12 & 33.8 & 47.5 & 40.71 \\
\hline \multirow{2}{*}{$\begin{array}{l}\text { Economic } \\
\text { dependence }\end{array}$} & Independent & 24.23 & 26.55 & 30.69 & 25.32 & 26.32 & 24.31 & 21.6 \\
\hline & Dependent & 75.77 & 73.45 & 69.31 & 74.68 & 73.68 & 75.69 & 78.4 \\
\hline \multirow[t]{2}{*}{ Source of finance } & Household saving/income & 89.64 & 95.22 & 97.31 & 91.65 & 89.74 & 94.55 & 84.28 \\
\hline & $\begin{array}{l}\text { Other** (borrowing/sale of asset/ } \\
\text { contribution from relatives) }\end{array}$ & 18.86 & 4.78 & 2.69 & 8.35 & 10.26 & 5.45 & 15.72 \\
\hline \multirow[t]{3}{*}{ Ailment } & Chronic NCD & 50.06 & 49.55 & 46.96 & 49.33 & 50.92 & 55.23 & 48.72 \\
\hline & Communicable disease & 17.56 & 17.38 & 20.02 & 17.28 & 16.5 & 14.73 & 18.99 \\
\hline & Others & 32.38 & 33.07 & 33.02 & 33.39 & 32.58 & 30.04 & 32.29 \\
\hline \multirow[t]{2}{*}{ Health scheme } & Covered & 27.37 & 28.8 & 24.39 & 8.21 & 20.53 & 16.75 & 42.69 \\
\hline & Not covered & 72.63 & 71.2 & 75.61 & 91.79 & 79.47 & 83.25 & 57.31 \\
\hline \multirow[t]{2}{*}{ Surgery status } & Surgery needed & 30.73 & 33.92 & 15.98 & 29.93 & 27.22 & 34.97 & 30.41 \\
\hline & Surgery not needed & 69.27 & 66.08 & 84.02 & 70.07 & 72.78 & 65.03 & 69.59 \\
\hline \multicolumn{2}{|c|}{ Average family size } & 4.91 & 5.42 & 5.17 & 5.67 & 4.61 & 4.99 & 4.27 \\
\hline \multicolumn{2}{|c|}{ Average MPCE (Rs) } & 13659.91 & 17079.4 & 12741.68 & 12321.2 & 11261.6 & 15626.7 & 12658.31 \\
\hline \multicolumn{2}{|c|}{ Duration of hospitalization(days) } & 7.17 & 6.65 & 7.07 & 7.22 & 6.67 & 7.02 & 7.85 \\
\hline
\end{tabular}

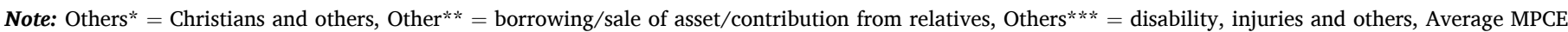

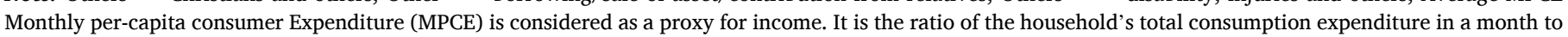

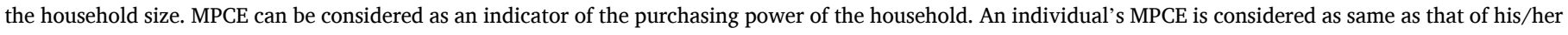
household. 
Comparing across regions nearly half of the sample respondents of the southern region $(42.6 \%)$ were covered under some health schemes, while the coverage was least in the central region (8.2\%).

The average family size of the respondents varies from four to six members. The average duration of hospitalization ranges from six to seven days. Monthly per capita consumption expenditure (MPCE), considered as a proxy for income, is reported to be the highest in the northern region (INR 17079), followed by the western region (INR 15626), the northeast region (INR 12741), southern region (INR 12658), central region (INR 12321), eastern region (INR 11261).

\subsection{Choice of health care across regions of India}

Tables 2 and 3 represent both inpatient expenditure and pattern of health care utilization across regions. Regardless of regions, the average spending incurred on inpatient health care by the elderly who have opted for private hospitals is almost five times higher than that of those who have chosen public ones. The National Sample Survey (NSSO) data also revealed that on an average OOP expenditures in the private sector are almost five times higher than those in the public sector (INR 36,255 and INR 6729 respectively). ${ }^{5}$ Despite expensive private medical care services, overwhelmingly more enormous proportions of the elderly of the country still prefer private hospitalization over the public (Table- 3 ). This is line with the study by ${ }^{35}$ who found that the use of private health facilities was high compared to the use of government health facilities among Nepali older adults. Older Indian adults choose costly private hospitalization over public ones may indicate an inferior public healthcare system in the country, corroborating some earlier findings. $^{12,36}$

Analysis reveals that the choice of hospitalization varies across the region. Further studies also have indicated substantial differences in inpatient care utilization by state. ${ }^{37,38}$ Across all regions, there was a statistically significant difference in the use of inpatient services between public and private hospitals. Such variations could be attributed to the differences in health care policies and associated facilities including many other individual factors. ${ }^{39}$ Comparing across regions; it is evident that private hospitalization is higher in the northern, central, western, and southern regions of the country, while in eastern and north-eastern regions, public hospitalization is higher. The utilization of general inpatient services is about three times higher than private facilities in the north-eastern region, suggesting thereby extreme dependence on the former among the elderly. These could signify two things, while on the one hand, the non-affordability of private health care services among these people could be the reason behind preference for the public health services; the possibility of poor or inadequate private health care system may also be behind this. The difference in the usage of inpatient services between public and private hospitals is statistically significant across all the regions.

\subsection{Factors determining the choice of hospitalization}

Table 4 shows the results of the logistic regression based on Andersen's HBM. It is interesting to note, unlike HBM, not all the variables are necessary predictors of choice of hospitals in India, particularly for the

Table 2

Private-Public differences in inpatient out-of-pocket expenditure across regions.

\begin{tabular}{lllll}
\hline Region & Private Hospital & Public hospital & Mean difference & t value\# \\
\hline Northern & 57918.6 & 13483.2 & 44435.4 & $-16.1^{*}$ \\
North-east & 63435.06 & 12129.8 & 51305.3 & $-6.1^{*}$ \\
Central & 42949.92 & 11954.2 & 30995.7 & $-13.2^{*}$ \\
Eastern & 59438.35 & 7552.29 & 51886.1 & $-14.2^{*}$ \\
Western & 52790.94 & 14234.8 & 38556.1 & $-12.3^{*}$ \\
Southern & 46316.83 & 6292.4 & 40024.4 & $-24.09^{*}$ \\
Overall & 51129.82 & 10357.2 & 50099.7 & $-37.41^{*}$ \\
\hline
\end{tabular}

Note: * $-\mathrm{p}<0.001$, significance at $5 \%$; \#- $t$-test for unequal variance.
Table 3

Utilization of private-public inpatient services by elderly across regions.

\begin{tabular}{lllll}
\hline Region & Private & Public & Difference & Z value \\
\hline North & 51.6 & 48.4 & 3.2 & $-1.5^{*}$ \\
Central & 62.9 & 37.1 & 25.8 & 8.8 \\
East & 40 & 60 & -20 & -5.9 \\
Northeast & 21 & 79 & -58 & $-18.7^{*}$ \\
West & 68.2 & 31.8 & 36.4 & 15.5 \\
South & 61.6 & 38.4 & 23.2 & $16.5^{*}$ \\
Total & 57.1 & 42.9 & 14.2 & $9.6^{*}$ \\
\hline
\end{tabular}

Note: * $-\mathrm{p}<0.001$, significance at $5 \%$.

Factors determining the choice of hospitalization.

elderly. However, as most of the variables turn out to be significant, and the results are on expected lines, the HBM model has relevance in the Indian context.

\subsubsection{Predisposing factors}

The results of the logistic regression for each region are further shown separately in Table 4. It is important to note that the set of variables significant in one region is not substantial in another region. To be specific, education and caste are substantial determinants in all the regions, among the predisposing factors. Other studies also found that education has an important role too in utilization of health care services by an individual. ${ }^{14}$ People who are well educated are said to be well informed, allowing them to make reasonable decisions concerning health care utilization. ${ }^{40}$ In the eastern, north-eastern, central, and southern regions, the literate older adults are more likely to choose private hospitalization than the illiterate older adults. The caste category determines the choice of health care centers across all the regions. The elderly belonging to the other backward classes and other communities are more likely to avail of private health services than their scheduled castes and scheduled tribes counterparts. On the contrary, the upper caste elderly tend to prefer private health services over the public, confirming the findings of an earlier study. ${ }^{14}$ In the northern and north-east regions, the older adults belonging to the Muslim religion are 20 and $40 \%$ less likely to choose private hospitalization than the Hindus. But in the southern region, the elderly belonging to the Muslim religion are more likely to avail private health facilities.

\subsubsection{Enabling factors}

Among the enabling factors, monthly household income per capita plays a significant role in determining health care utilization across all the regions. The analysis shows that the likelihood of choosing private hospitals over public ones increases with increasing MPCE. Higher MPCE reflects higher purchasing power of the individuals as well as their families, indicating thereby greater affordability of expensive private health care services. ${ }^{44}$

The analysis also revealed the significant differences between rural and urban areas in selecting health care services in the northern and eastern regions. The rural-urban and regional variations in the distribution of public facilities and human resources are well known. ${ }^{22}$ In the north and east region, the elderly belonged to the urban areas were more likely to avail private health services. The impact of household size on decision making came out to be significant in the western and southern regions, where utilization of private health services decreased with increasing family size. This is line with the earlier study by. ${ }^{41}$ It may indicate that support/caregiving for elderly populations imposes an economic burden on the families. So due to financial constraint elderly belonging to a larger family tends to utilize more public health services over the private.

The effect of economic dependence was also not uniform across the region. Economically independent elderly belonged to the southern region was more likely to prefer private inpatient services to public ones than their financially dependent counterparts. It is interesting to note that economically independent elderly belonged to the central region 
Table 4

Results of logistic regression on the determinants of the choice of hospital services by geriatric population across the region, 2017-2018.

\begin{tabular}{|c|c|c|c|c|c|c|c|c|c|c|c|c|}
\hline \multirow[t]{3}{*}{ Variables } & \multicolumn{12}{|l|}{ Regions } \\
\hline & \multicolumn{2}{|l|}{ NORTH } & \multicolumn{2}{|c|}{ NORTH-EAST } & \multicolumn{2}{|l|}{ CENTRAL } & \multicolumn{2}{|l|}{ EAST } & \multicolumn{2}{|l|}{ WEST } & \multicolumn{2}{|l|}{ SOUTH } \\
\hline & Odds ratio & $95 \% \mathrm{CI}$ & Odds ratio & $95 \% \mathrm{CI}$ & Odds ratio & $95 \% \mathrm{CI}$ & Odds ratio & $95 \% \mathrm{CI}$ & Odds ratio & $95 \% \mathrm{CI}$ & Odds ratio & $95 \% \mathrm{CI}$ \\
\hline \multicolumn{13}{|l|}{ Age group } \\
\hline \multicolumn{13}{|l|}{$60-69 \AA$} \\
\hline 70-79 & 0.994 & {$[0.818,1.207]$} & 1.18 & {$[0.820,1.697]$} & 0.968 & {$[0.773,1.211]$} & 1.028 & {$[0.818,1.292]$} & 0.896 & {$[0.708,1.135]$} & 0.856 & {$[0.731,1.003]$} \\
\hline $80+$ & 0.93 & {$[0.696,1.244]$} & 1.016 & {$[0.595,1.735]$} & 1.395 & {$[0.975,1.996]$} & 0.919 & {$[0.654,1.290]$} & 0.86 & {$[0.603,1.226]$} & 1.122 & {$[0.891,1.413]$} \\
\hline \multicolumn{13}{|l|}{ Sex } \\
\hline \multicolumn{13}{|l|}{ Male ${ }^{\circledR}$} \\
\hline Female & 1.114 & {$[0.905,1.370]$} & 1.375 & {$[0.961,1.966]$} & 0.923 & {$[0.728,1.169]$} & 1.219 & {$[0.964,1.540]$} & 1.111 & {$[0.880,1.401]$} & 0.967 & {$[0.831,1.126]$} \\
\hline \multicolumn{13}{|l|}{ Place of residence } \\
\hline \multicolumn{13}{|l|}{ Rural ${ }^{\circledR}$} \\
\hline Urban & $1.519^{* * * *}$ & {$[1.245,1.854]$} & 0.784 & {$[0.539,1.139]$} & 0.838 & {$[0.659,1.064]$} & $1.369^{* *}$ & {$[1.080,1.735]$} & 1.015 & {$[0.791,1.303]$} & 0.888 & {$[0.760,1.037]$} \\
\hline $\begin{array}{l}\text { Household size } \\
\text { Religion }\end{array}$ & 0.997 & {$[0.959,1.037]$} & 0.944 & {$[0.857,1.039]$} & 0.962 & {$[0.922,1.004]$} & 1.002 & {$[0.954,1.053]$} & $0.948^{*}$ & {$[0.906,0.993]$} & $0.925^{* * * *}$ & {$[0.890,0.961]$} \\
\hline \multicolumn{13}{|l|}{ Hindu ${ }^{\circledR}$} \\
\hline Muslim & $0.249 * * * *$ & {$[0.181,0.341]$} & $0.423^{*}$ & {$[0.186,0.959]$} & 0.804 & {$[0.587,1.099]$} & 0.847 & {$[0.604,1.186]$} & 0.787 & {$[0.541,1.144]$} & $1.274^{*}$ & {$[1.027,1.580]$} \\
\hline Others & 1.266 & {$[0.986,1.625]$} & $1.878^{* *}$ & {$[1.172,3.007]$} & 1.802 & {$[0.702,4.629]$} & $7.034^{* * * *}$ & {$[2.221,22.27]$} & $0.587^{* * *}$ & {$[0.400,0.861]$} & 0.911 & {$[0.715,1.160]$} \\
\hline \multirow{2}{*}{\multicolumn{13}{|c|}{$\begin{array}{l}\text { Social group } \\
\text { SC/ST } ®\end{array}$}} \\
\hline \multicolumn{9}{|l|}{$\mathrm{SC} / \mathrm{ST} \circledast$} & & & & \\
\hline OBC & $1.433^{* * *}$ & {$[1.103,1.862]$} & $2.207^{* *}$ & {$[1.367,3.565]$} & 1.281 & {$[0.974,1.686]$} & $1.770^{* * * *}$ & {$[1.301,2.408]$} & 1.278 & {$[0.934,1.749]$} & $1.830^{* * * *}$ & {$[1.497,2.236]$} \\
\hline Others & $1.421^{* *}$ & {$[1.129,1.788]$} & 2.131 ** & {$[1.245,3.647]$} & $1.745^{* * * *}$ & {$[1.264,2.408]$} & $1.792^{* * * *}$ & {$[1.338,2.401]$} & $1.668^{\text {*** }}$ & {$[1.226,2.269]$} & $2.673^{* * * *}$ & {$[2.111,3.384]$} \\
\hline \multirow{2}{*}{\multicolumn{13}{|c|}{$\begin{array}{l}\text { Education } \\
\text { Literate }\end{array}$}} \\
\hline & & & & & & \multicolumn{7}{|c|}{ Literate } \\
\hline Illiterate & 1.129 & {$[0.912,1.398]$} & $1.968^{* *}$ & {$[1.312,2.951]$} & $1.286^{*}$ & {$[1.001,1.651]$} & $1.724^{* * * *}$ & {$[1.356,2.193]$} & 1.27 & {$[0.996,1.619]$} & $1.285^{* *}$ & {$[1.099,1.502]$} \\
\hline MPCE & $1.000^{* * * * *}$ & {$[1.000,1.000]$} & $1.000^{* * * *}$ & {$[1.000,1.000]$} & $1.000^{* * * *}$ & {$[1.000,1.000]$} & $1.000^{* * * *}$ & {$[1.000,1.000]$} & $1.000^{* * * *}$ & {$[1.000,1.000]$} & $1.000^{* * * *}$ & {$[1.000,1.000]$} \\
\hline \multicolumn{13}{|l|}{ Source of finance } \\
\hline \multicolumn{13}{|l|}{ Household income/saving ${ }^{\circledR}$} \\
\hline Others & $1.636^{*}$ & {$[1.085,2.465]$} & 1.99 & {$[0.726,5.453]$} & $0.426 * * * *$ & {$[0.300,0.604]$} & 1.206 & {$[0.861,1.687]$} & 1.479 & {$[0.921,2.377]$} & 1.096 & {$[0.889,1.352]$} \\
\hline \multicolumn{13}{|l|}{ Economic dependence } \\
\hline Dependent ${ }^{\circledR}$ & & & & & & & & & & & & \\
\hline independent & 0.962 & {$[0.772,1.200]$} & 1.283 & {$[0.862,1.910]$} & $0.728^{*}$ & {$[0.563,0.941]$} & 1.257 & {$[0.972,1.625]$} & 1.281 & {$[0.975,1.683]$} & $1.254^{*}$ & {$[1.049,1.498]$} \\
\hline Health scheme & & & & & & & & & & & & \\
\hline Covered $₫$ & & & & & & & & & & & & \\
\hline Not covered & $0.686^{* * * *}$ & {$[0.558,0.843]$} & $2.017^{* *}$ & {$[1.254,3.245]$} & 1.15 & {$[0.840,1.574]$} & 0.898 & {$[0.687,1.173]$} & $1.573^{* *}$ & {$[1.184,2.090]$} & $1.213^{* * *}$ & {$[1.048,1.404]$} \\
\hline Surgery & & & & & & & & & & & & \\
\hline Received $₫$ & & & & & & & & & & & & \\
\hline Not received & $0.469^{* * * *}$ & {$[0.386,0.570]$} & $0.237^{* * *}$ & {$[0.162,0.345]$} & $0.642^{* * * *}$ & {$[0.508,0.811]$} & $0.313^{* * * *}$ & {$[0.248,0.395]$} & 0.879 & {$[0.698,1.107]$} & $0.599^{* * * *}$ & {$[0.508,0.706]$} \\
\hline Disease & & & & & & & & & & & & \\
\hline Communicable disease ${ }^{\circledR}$ & & & & & & & & & & & & \\
\hline Non-communicable disease & 0.969 & {$[0.758,1.238]$} & $2.171^{* *}$ & {$[1.312,3.593]$} & 1.224 & {$[0.919,1.630]$} & $1.415^{*}$ & {$[1.034,1.936]$} & 1.077 & {$[0.794,1.460]$} & 1.138 & {$[0.940,1.377]$} \\
\hline Others & 1.024 & {$[0.787,1.334]$} & 1.625 & {$[0.957,2.762]$} & $1.499^{* *}$ & {$[1.103,2.037]$} & $2.019^{* * * *}$ & {$[1.451,2.810]$} & 1.146 & {$[0.818,1.607]$} & 1.118 & {$[0.910,1.374]$} \\
\hline Duration of stay in hospital & 0.999 & {$[0.989,1.009]$} & 1.004 & {$[0.985,1.023]$} & 0.994 & {$[0.984,1.003]$} & 1.003 & {$[0.993,1.014]$} & $0.987^{*}$ & {$[0.975,0.999]$} & $0.993^{*}$ & {$[0.986,1.000]$} \\
\hline
\end{tabular}

Note: ${ }^{\circledR}$ Reference category; ${ }^{*} p<0.05,{ }^{* *} p<0.01,{ }^{* * *} p<0.001$. 
was $70 \%$ less likely to avail private health services than their financially dependent counterparts. These may indicate the provision of a better public health system in this region. In all regions except the central and eastern, health-scheme coverage was found to be a significant factors in older individuals' choice of health care services. The analysis revealed that, with the exception of the northern region, elderly covered under any health scheme in the north-east, west, and southern regions were more likely to choose public hospitals, confirming Awoke and his coauthors' findings. ${ }^{42}$ Elderly patients are required to be admitted to public or government-aided hospitals to avail of health scheme facilities. The analysis revealed the same that the elderly who were not covered by any program for health expenditure support were less likely to avail of the public health services than private in the north-eastern, western, and southern regions.

\subsubsection{Need factors}

Among the need factors, disease conditions were significant in the north-eastern, central, and eastern regions, where the elderly were more likely to avail of the private health care services for non-communicable and other diseases. Although NCD prevention and treatment is unaffordable for many people, they are more likely to avail of private health facilities because there are no such government-sponsored NCD screening programs. The perceived need for health care was also an important determinant of health care utilization among the elderly in most of the region supporting the findings of. ${ }^{30}$

The need for surgery and private hospitalization had a positive association in the northern, eastern, north-eastern, central, and southern regions. It indicated that private health care centers may have efficiency incentives to provide better service than government bodies. Previous studies have shown that among all the regions, the southern region closely follows the Andersen model as almost all the enabling and need factors turn out to be significant. ${ }^{32}$ It is worth mentioning that the finding of the present study is also consistent with the previous studies.

\section{Conclusion}

The study's finding contributes to the existing field of research on the choice of health care in the context of Indian in several ways. It shows that the public sector has not been a choice for inpatient care for most of the population across Indian states. It establishes that apart from the financial factors, socio-demographic as well as the need factors are equally important in decision making concerning health care utilization. By and large, there appeared a distinct geographical pattern that explained state differentials in the utilization of the two different health care services across the country. The present study shows that the growth of private health care providers in the hilly north-eastern region of India has not grown as much as in India's central and southern states, supporting the finding of. ${ }^{43}$ It may be because the level of urbanization or access to nearby, developed urban areas is positively associated with the development of private health services.

Deficiency of human resources in health occurs at several levelsbetween regions, between rural and urban areas, and between public and private sectors. As the health care resources are unevenly distributed across the country, especially the north-eastern states, do not receive the attention of the private sector in health care. Adequate public sector provisioning while improving the quality would be of immense help to these otherwise disadvantaged regions. The efforts towards optimal allocation of resources across the regions would ensure equitable health care facilities across the country. In the face of limited government resources, "public-private-partnership" may help laggard sectors overcome the deficiency of health infrastructure. The evidence has shown a significant difference in the cost of treatment between public and private hospitals. Hence, there is a need to bring about healthcare pricing regulations among private hospitals without compromising healthcare quality. Further, since each region of the country bears different characteristics, the healthcare policy needs to be sensitive to the specific regional requirements. In this respect, special attention needs to be given to the backward regions of the country.

The study carries significance from the following standpoints. The cost of health care utilization varies according to its types; while private health care services involve higher prices, the quality of services associated with the private sector is usually considered better than the public sector. Thus, it is significant to understand the preference pattern of the Indian geriatric population towards health services and consequent financial implications upon them in this context.

\section{Funding}

The authors received no financial support for the research, authorship and/or publication of this article.

\section{Availability of data and material}

This research work was performed based on secondary data which is freely available in public domain at MOSPI, India website (Source of data:http://www.mospi.gov.in/).

\section{Ethics approval \& consent to participate}

This research does not have an ethical code because this research work was performed based on secondary data which is freely available in domain at MOSPI, India website (Source of data:http://www.mospi. gov.in/) and thus author does not require any ethical clearance and consent to participate.

\section{Consent for publication}

Not applicable.

\section{Declaration of competing interest}

The authors declare that they have no competing interests.

\section{Acknowledgements}

We appreciate the NSS Office, Government of India for the preliminary version of the 75th round of data on "Social Consumption: Health", which is used for the analyses in this manuscript. In addition, the authors are thankful to Mr Ajit Kumar Jaiswal for his valuable feedback to enrich this paper.

\section{List of abbreviations}

$\begin{array}{ll}\text { NSS } & \text { National Sample survey } \\ \text { OOP } & \text { Out of Pocket } \\ \text { MPCE } & \text { Monthly per capita expenditure } \\ \text { WHO } & \text { World Health Organization } \\ \text { CI } & \text { Confidence Interval } \\ \text { NCD } & \text { Non-communicable diseases }\end{array}$

\section{References}

1 Oladipo JA. Utilization of health care services in rural and urban areas: a determinant factor in planning and managing health care delivery systems. Afr Health Sci. 2014;14:322-333. https://doi.org/10.4314/ahs.v14i2.6.

2 Mackintosh Maureen, Amos Channon, Karan Anup, Selvaraj Sakthivel, Cavagnero Eleonora, Zhao Hongwen. What is the private sector? Understanding private provision in the health systems of low-income and middle-income countries. Lancet. 2016;388:596-605. https://doi.org/10.1016/S0140-6736(16)00342-1.

3 Katyal Anuradha, Prabal Vikram Singh, Bergkvist Sofi, Amit Samarth, Rao Mala. Private sector participation in delivering tertiary health care: a dichotomy of access and affordability across two Indian states. Health Pol Plann. 2015;30:i23-i31. https:// doi.org/10.1093/heapol/czu061. 
4 Bhat Ramesh. Regulation of the private health sector in India. Int $J$ Health Plann Manag. 1996;11:253-274. https://doi.org/10.1002/(SICI)1099-1751(199607)11: $3<253:$ :AID-HPM435>3.0.CO;2-N.

5 NSSO. Key Indicators of Social Consumption in India: Health, 71st Round (January-June 2014). Ministry of Statistics and Programme Implementation, Government of India; 2014.

6 Jain Nishant, Kumar Alok, Nandraj Sunil, Melo Furtado Kheya. NSSO 71st round: same data, multiple interpretations. Economic and political weekly 50. Econ Polit Wkly. 2015:84-87.

7 Dilip TR. Utilization of inpatient care from private hospitals: trends emerging from Kerala, India. Health Pol Plann. 2010;25:437-446. https://doi.org/10.1093/heapol/ czq012.

8 Forgia Gerard La, Nagpal Somil. Government-Sponsored Health Insurance in India: Are You Covered. World Bank Publications; 2012.

9 World Health Organization. Global Health Observatory Data Repository 2020. Passive Surveillance (PS) during Interruption. 2020.

10 World Health Organization. Global Spending on Health: A World in Transition. World Health Organization; 2019.

11 NSS. National Sample Survey Organization. NSS 71st Round - Health in India. New Delhi: Government of India; 2015.

12 Alam Moneer, Karan Anup. Elderly Health in India: Dimension, Differentiatials and Determinats. UNFPA; 2011. https://doi.org/10.13140/2.1.4232.5128.

13 Peltzer Karl, Jennifer Stewart Williams, Paul Kowal, et al. Universal health coverage in emerging economies: findings on health care utilization by older adults in China, Ghana, India, Mexico, the Russian Federation, and South Africa. Glob Health Action. 2014;7. https://doi.org/10.3402/gha.v7.25314. Taylor \& Francis: 25314.

14 Dey Dipanjan Kumar, Mishra Vishal. Determinants of choice of healthcare services utilization: empirical evidence from India. Indian J Community Health. 2014;26: 356-363.

15 Mohanty Sanjay K, Chauhan Rajesh K, Mazumdar Sumit, Srivastava Akanksha. Outof-pocket expenditure on health care among elderly and non-elderly households in India. Soc Indicat Res. 2014;115:1137-1157. https://doi.org/10.1007/s11205-0130261-7.

16 Lee Ting-Hsuan J, Saran Indrani, Rao Krishna D. Ageing in India: financial hardship from health expenditures. Int J Health Plann Manag. 2018;33:414-425. https://doi. org/10.1002/hpm.2478.

17 Sekhri Neelam, Savedoff William. Private health insurance: implications for developing countries. Bull World Health Organ. 2005;12.

18 Bhat Ramesh, Jain Nishant. Analysis of public expenditure on health using state level data. 2004. Working Paper.

19 Peters D, Rao K, Ramana GNV. Reaching the Poor with Health, Nutrition, and Population Services: What Works, what Doesn't, and Why. World Bank Publications; 2004.

20 MOHFW. National Health Accounts, India (2004-05). National health accounts cell, Ministry of health and family welfare, Government of India; 2009.

21 Russell Steven. Ability to pay for health care: concepts and evidence. Health Pol Plann. 1996;11:219-237. https://doi.org/10.1093/heapol/11.3.219.

22 Duggal Ravi. Poverty \& health: criticality of public financing. Indian J Med Res. 2007; 126:309-317.

23 Pal Rama. Analysing catastrophic OOP health expenditure in India: concepts, determinants and policy implications. 2012. Working Paper.

24 Bhat Ramesh. The private/public mix in health care in India. Health Pol Plann. 1993; 8:43-56. https://doi.org/10.1093/heapol/8.1.43.

25 Bhat Ramesh. Characteristics of private medical practice in India: a provider perspective. Health Pol Plann. 1999;14:26-37. https://doi.org/10.1093/heapol/ 14.1.26.
26 Suchman Edward A. Stages of illness and medical care. J Health Hum Behav. 1965;6: 114-128. https://doi.org/10.2307/2948694 [American Sociological Association, Sage Publications, Inc.]

27 Young James C. Non-use of physicians: methodological approaches, policy implications, and the utility of decision models. Soc Sci Med Part B Med Anthropol. 1981;15:499-507. https://doi.org/10.1016/0160-7987(81)90024-7.

28 Rosenstock Irwin M, Strecher Victor J, Becker Marshall H. The health belief model and HIV risk behavior change. In: DiClemente Ralph J, Peterson John L, eds. Preventing AIDS: Theories and Methods of Behavioral Interventions. Boston, MA: Springer US; 1994:. 5-24. AIDS Prevention and Mental Health.

29 Andersen Ronald, Newman John F. Societal and individual determinants of medical care utilization in the United States. Milbank Q. 2005;83. https://doi.org/10.1111/ j.1468-0009.2005.00428.x. Online-only-Online-only.

30 Aday, Lu Ann, Andersen Ronald. A framework for the study of access to medical care. Health Serv Res. 1974;9. Health Research \& Educational Trust: 208.

31 Kant S, Mishra P, Goswami A. Morbidity among elderly persons residing in a resettlement colony of Delhi. Indian J Prev Soc Med. 2004;35:1-8.

32 Chatterjee Chandrima, Chandra Nayak Narayan, Mahakud Jitendra, Chatterjee Suhita Chopra. Factors affecting the choice of health care utilisation between private and public services among the elderly population in India. Int $J$ Health Plann Manag. 2019;34:e736-e751. https://doi.org/10.1002/hpm.2686.

33 Mini GK. Pattern and correlates of chronic non-communicable diseases among older adults in selected states of India. BKPAI Working Paper Series No. 3. UNFPA. 2014. New Delhi.

34 Agrawal Gopal, Arokiasamy P. Morbidity prevalence and health care utilization among older adults in India. J Appl Gerontol. 2010;29:155-179. https://doi.org/ 10.1177/0733464809339622. SAGE Publications Inc.

35 Acharya Sabnam, Ghimire Saruna, Jeffers Eva M, Shrestha Naveen. Health care utilization and health care expenditure of Nepali older adults. Frontiers in Public Health. 2019;7:24. https://doi.org/10.3389/fpubh.2019.00024.

36 Anand Ankit. Inpatient and outpatient health care utilization and expenditures among older adults aged 50 years and above in India. Health Prospect. 2016;15: 11-19. https://doi.org/10.3126/hprospect.v15i2.15831.

37 Singh CH, Ladusingh L. Correlates of inpatient healthcare seeking behavior in India. Indian J Publ Health. 2009;53:6-12.

38 Mukherjee Subrata, Levesquel Jean-Frederic. Changing inequalities in utilisation of inpatient care in rural India: evidence from the NSS. Economic and political weekly 45. Econ Polit Wkly. 2010:84-91.

39 Chen Meng-Yu, Rose Charles E, Qi Yan Ping, et al. Defining the plasma folate concentration associated with the red blood cell folate concentration threshold for optimal neural tube defects prevention: a population-based, randomized trial of folic acid supplementation. Am J Clin Nutr. 2019;109:1452-1461. https://doi.org/ 10.1093/ajcn/nqz027.

40 Fletcher Jason M, Frisvold David E. Higher education and health investments: does more schooling affect preventive health care use? J Hum Cap. 2009;3:144-176. https://doi.org/10.1086/645090. The University of Chicago Press.

41 Halasa Y, Nandakumar AK. Factors determining choice of health care provider in Jordan. EMHJ - Eastern Mediterranean Health Journal. 2009;15(4):959-968, 2009.

42 Awoke Mamaru Ayenew, Negin Joel, Moller Jette, et al. Predictors of public and private healthcare utilization and associated health system responsiveness among older adults in Ghana. Global Health Action 10. Taylor \& Francis. 2017. https://doi. org/10.1080/16549716.2017.1301723, 1301723.

43 Kumar Chandan, Prakash Ravi. Public-private dichotomy in utilization of health care services in India. Consilience. Columbia University. 2011:25-52.

44 Yunus Noorâ€TMain, Mohamad, Hazilah Noor, et al. Determinants of healthcare utilisation among the elderly in Malaysia. Inst Econ. 2017:115-140. 